\title{
TRABALHO E UNIVERSIDADE: Reflexões Sobre o Perfil de Jovens Trabalhadores Egressos da Educação a Distância no Pará
}

\author{
João Batista do Carmo Silva ${ }^{1}$ \\ Benilda Miranda Veloso Silva ${ }^{2}$ \\ Cheliane Estumano Gaia ${ }^{3}$
}

\begin{abstract}
RESUMO
Esta pesquisa teve como objetivo analisar o processo de formação de egressos trabalhadores, investigando como ocorreu o método de inserção desses no mundo do trabalho, a fim de compreender a sua vida profissional após a conclusão de um curso de Graduação em uma instituição privada de Educação a Distância (EaD), assim como as implicações para a sua formação. Metodologicamente, este trabalho, segundo as bases de investigação, utilizou o materialismo histórico dialético, valendo-se da pesquisa qualitativa e do procedimento técnico denominado estudo de caso. Os dados foram coletados por meio de questionários socioeconômicos com licenciados do curso de Pedagogia e de entrevista semiestruturada. Assim, a partir dos resultados, é fato que a educação, oferecida pela referida instituição, contribuiu de forma significativa nos aspectos profissional e humano de seus egressos. Concluiu-se que existem contradições no perfil dos jovens universitários egressos da EaD, e que, em geral, suas possibilidades são consideradas positivas em decorrência da flexibilidade oferecida pela instituição, e o aspecto negativo dessa modalidade de ensino se encontra na interatividade com os tutores que não conseguem suprir as dificuldades dos alunos, tornando a relação tutor/aluno um obstáculo para a produção e a socialização do conhecimento.

Palavras-chave: Universidade. Trabalho. Formação. Educação a distância.
\end{abstract}

WORK AND UNIVERSITY:

ANALYSIS OF THE PROFILE OF YOUNG WORKERS EGRESSES FROM DISTANCE EDUCATION IN PARÁ

\section{ABSTRACT}

This research aimed to analyze the process of training of graduating workers, investigating how their method of insertion in the world of work occurred, in order to understand their professional life after completing an undergraduate course in a private institution of Education a Distance Learning (EaD), as well as the implications for their training. Methodologically, this work, according to the research bases, used dialectical historical materialism, making use of qualitative research and the technical procedure called case study. Data were collected through socioeconomic questionnaires with graduates from the Pedagogy Course and semi-structured interviews. Thus, based on the results, it is a fact that the education offered by that institution contributed significantly to the professional and human aspects of its graduates. It was concluded that there are contradictions in the profile of young university graduates from DE, and that, in general, their possibilities are considered positive, due to the flexibility offered by the institution, to which the negative aspect of this teaching modality is found in the interactivity with the students. tutors who are unable to meet students' difficulties, making the tutor / student relationship an obstacle to the production and socialization of knowledge.

Keywords: University. Work. Formation. Distance education.

Recebido em: 8/4/2020

Aceito em: $16 / 6 / 2020$

\footnotetext{
${ }_{1}^{1}$ Doutor em Educação (linha de Políticas Públicas Educacionais) pelo Programa de Pós-Graduação em Educação da UFPA (2016). Mestre em Educação pela UFPA (2009). Especialista em Educação Ambiental pela UFPA (2004). Pedagogo pela UFPA (2003). Professor-adjunto II da Universidade Federal do Pará - Campus Universitário do Tocantins (Cuntins), vinculado à Faculdade de Educação. http://lattes.cnpq. br/5437954641195296. https://orcid.org/0000-0002-3170-4735. jbatistacsilva@ufpa.br

2 Doutoranda no Programa de Pós-Graduação em Educação: Conhecimento e Inclusão Social, da Faculdade de Educação da UFMG (PPGE/ FaE/UFMG). Mestre em Comunicação, Linguagem e Cultura (2012). Especialista em Informática e Educação pela Universidade do Estado do Pará (2004). Graduada em Pedagogia pela Universidade Federal do Pará (2003). Especialista em Educação da Secretaria Estadual de Educação - Seduc-PA. http://lattes.cnpq.br/2806246270149753. https://orcid.org/0000-0003-0498-3481. bveloso@ufpa.br

3 Graduanda em Pedagogia pela Universidade Federal do Pará (UFPA) Campus Universitário do Baixo Tocantins - Cametá. Membro do grupo de Estudos e Pesquisas sobre a Universidade na Amazônia. http://lattes.cnpq.br/6282505591518810. https://orcid.org/0000-0002-2353-764X. shelianegaia@gmail.com
} 
O presente trabalho apresenta os resultados finais da pesquisa decorrente de uma reflexão sobre as categorias Formação, Trabalho e Universidade, a qual ocorreu no Estado do Pará, no município de Cametá, em uma instituição de Ensino Superior privada que trabalha com Educação a Distância, onde se analisou o processo de formação e inserção de trabalhadores egressos no mundo do trabalho, no sentido de explicitar as implicações resultantes desta inserção, considerando que sua formação se deu na modalidade a distância.

Isso foi feito com os seguintes intuitos: identificar o número de alunos formados, no período de 2015 a 2017, no Curso de Pedagogia da referida instituição; realizar o levantamento do perfil socioeconômico de jovens egressos do curso de Pedagogia da instituição analisada; investigar as especificidades do processo formativo ofertado pela mesma, por meio da Educação a Distância, visando à formação de jovens trabalhadores egressos; e analisar as relações estabelecidas entre a formação acadêmica universitária e as atividades laborativas desenvolvidas pelos jovens egressos do curso de Pedagogia.

Nesse sentido, a presente pesquisa apresenta resultados de imensurável importância no debate sobre a formação e a inserção de egressos no mercado de trabalho, no bojo de uma temática específica que é a relação entre trabalho e universidade.

Esta pesquisa tratou sobre a importância do processo de formação para esses egressos trabalhadores, e em que estágio os mesmos se encontram, tendo em vista a ocorrência de um cenário problemático surgido há muito tempo, em que as Universidades Públicas não dão conta de suprir toda a demanda da sociedade, fazendo com que os jovens escolham, como solução, a entrada em uma Instituição Privada, na maioria das vezes, sob a modalidade EaD, sendo essa, para a maioria dos estudantes, segundo Alves (2008, p. 250), "[...] a porta que lhe abre quando a do ensino público se fecha".

As universidades públicas não possuem condições para atender o grande número de alunos que precisa acessar o Ensino Superior. Para a Universidade Federal do Pará (PORTAL..., 2019), no ano de 2018, de acordo com o seu site oficial, foram ofertadas 7.286 vagas para 88.376 candidatos inscritos. Diante disso, é possível perceber que significativa parte dos candidatos ficou de fora dessa opção de Ensino Superior, geralmente tendo, como única escolha de formação, a educação privada presencial ou a distância.

A educação a distância surge, de acordo com Arruda e Arruda (2015, p. 323), no início do século 19. O seu marco regulatório, entretanto, ocorre com a promulgação da Lei no 9.394 de 1996 (Diretrizes e Bases da Educação - LDB), quando é estabelecido, no artigo 80: “O Poder Público incentivará o desenvolvimento e a vinculação de programas de ensino a distância, em todos os níveis de ensino, e de educação continuada" (BRASIL, 1996, p. 43).

A EaD contribui, portanto, de forma significativa para que o processo de democratização do Ensino Superior ocorra de maneira mais ampla, permitindo um avanço de possiblidades para esse nível de ensino. 
Essa modalidade de educação oferece alternativas flexíveis para o processo de ensino, tendo em vistas que o aluno comparece na instituição apenas uma vez por semana, fazendo com que o curso a distância seja a solução para quem não pode estar sempre presente na sala de aula, possibilitando, assim, o desenvolvimento de várias atividades, sem que isso venha a comprometer a sua vida social fora da instituição.

A instituição pesquisada, segundo informações do seu site oficial, atualmente está com mais de 185 mil alunos em cursos de Graduação e Pós-Graduação presenciais e a distância, sendo considerada a maior Instituição Privada de Ensino Superior de Santa Catarina e uma das maiores do Brasil. No momento, a mesma está presente em todas as regiões do país, com mais de 400 polos EaD e 10 unidades próprias de ensino presencial.

Ainda de acordo com o seu portal, no Pará, está presente em 27 cidades, e no município de Belém está instalada em quatro lugares diferentes. Ou seja, há 30 polos da instituição no Estado. No município onde a instituição pesquisada se encontra (Cametá), a mesma oferece, atualmente, 38 opções de cursos, distribuídos entre as modalidades Bacharelado, Licenciatura e Superior de Tecnologias (tecnólogo).

Mesmo, no entanto, com os avanços e possibilidades que a instituição possibilita, esta enfrenta várias críticas em relação à sua expansão e à qualidade de ensino ofertado, havendo, dessa forma, um elevado número de ofertas de cursos sem que se pense neles qualitativamente, sem falar que nem todos têm acesso aos meios tecnológicos oferecidos por essa instituição.

Com base no exposto, este artigo organiza-se em três seções, cabendo a primeira justificar o método utilizado na pesquisa, ressaltando o porquê da escolha do embasamento teórico; a segunda apresenta os resultados alcançados com a pesquisa de campo, a fim de visualizar e analisar os dados encontrados; a última seção, por sua vez, apresenta a discussão realizada a partir de categorias essenciais da pesquisa, com o uso da sistematização e análise de dados; por fim, estão dispostas as referências bibliográficas, nas quais são informadas as fontes de consulta utilizadas para o aporte teórico desta pesquisa.

A presente pesquisa, segundo as bases lógicas da investigação, utiliza-se do materialismo histórico dialético, valendo-se da pesquisa qualitativa e do procedimento técnico denominado estudo de caso. Vale-se, aqui, do materialismo histórico dialético como método de pesquisa, tendo em vista a busca pela realização de uma investigação crítica e reflexiva, em que o conhecimento se pauta na transformação da realidade, como bem ressalta Frigotto (1991), ou seja, que o fundamental é a produção de um conhecimento crítico que possibilite a transformação da realidade.

Esse método usa tanto a pesquisa qualitativa quanto a quantitativa como ferramentas, junção essa que apresenta várias dicotomias, quando ambas não podem, $a$ priori, atuar em conjunto. No âmbito do materialismo histórico dialético, no entanto, ambas se complementam. Como salienta Marques (1997), elas não estão em oposição; pelo contrário, vão se complementando no processo de produção do conhecimento científico. 
Além disso, nesta investigação, de acordo com Bogdan e Bilken (1994), os dados recolhidos são designados como qualitativos, o que significa que são ricos em fenômeno descritivo relativamente a pessoas, locais e conversas, e complexos no que se refere ao tratamento estatístico, o que pressupõe uma problematização da realidade com base em dados empíricos. Ou seja, os dados são coletados e analisados com base em um referencial teórico. Por conseguinte, ainda na concepção dos referidos autores, a pesquisa de cunho qualitativo procura a lógica da construção de conhecimento, tanto para o investigador quanto para todos os envolvidos na pesquisa, ou seja, para toda a sociedade em geral.

Posteriormente, o propósito do estudo de caso é reunir informações detalhadas e sistemáticas sobre um fenômeno. Isso é essencial para que se realize um processo de análise, compreensão e objetividade aprofundada da pesquisa. Chizzotti (2010, p. 136) afirma:

Os estudos de casos visam explorar, deste modo, um caso singular, situado na vida real contemporânea, bem delimitado e contextualizado, em tempo e lugar para realizar uma busca circunstanciada de informações sobre um caso específico.

Assim, o estudo de caso auxilia nas análises realizadas e nos resultados encontrados na pesquisa. Nesse sentido, é possível reunir informações detalhadas no contexto da realidade dos egressos da instituição.

As etapas da pesquisa percorrem a proposta de critérios que englobaram três fases: pesquisa bibliográfica e sessão de estudo, pesquisa de campo e análise e sistematização de dados.

A primeira fase, relacionada à pesquisa bibliográfica, tem a finalidade de realizar um levantamento bibliográfico sobre os debates que vêm sendo realizados em torno da temática da pesquisa. Nesse processo, recolhem-se artigos em periódicos, livros, capítulos de livros, teses e dissertações em meio digital e bibliotecas.

Essa fase é de extrema importância, pois, de acordo Boccato (2006, p. 266),

[...] a pesquisa bibliográfica busca a resolução de um problema (hipótese) por meios de referenciais teóricos publicados, analisando e discutindo as várias contribuições científicas.

A segunda fase está relacionada com a pesquisa de campo, em que, segundo Severino (2002), o objeto/fonte é abordado em seu meio ambiente próprio, nas condições naturais em que os fenômenos ocorrem, sendo, assim, diretamente observado. A pesquisa de campo adota como instrumento de coleta de dados a aplicação de questionário e entrevista semiestruturada.

O questionário é um instrumento de investigação destinado à coleta de dados, baseando-se, geralmente, na investigação de um grupo representativo da população em estudo. Trata-se de um conjunto de perguntas ordenadas de acordo com um critério predeterminado, que deve ser respondido sem a presença do entrevistador (LAKATOS; MARCONI, 2003). 
Por esse motivo, opta-se, aqui, por realizar a aplicação do questionário via internet, tendo em vista acreditar ser esse método mais viável, em se tratando de egressos. Além disso, a instituição pesquisada alegou que a maioria desses egressos reside em localidades distintas do lócus da pesquisa, fator fundamental para que houvesse um número inferior de alunos que responderam ao questionário, levando-se em conta o total de alunos concluintes.

Os questionários utilizados nesta pesquisa foram aplicados com os 14 egressos trabalhadores localizados, oriundos das turmas de Licenciatura em Pedagogia concluídas no período de 2015 a 2016 (o objetivo era analisar os anos de 2015 a 2017, no entanto não foi possível obter os dados do ano de 2017, ficando somente a análise dos anos de 2015 e 2016), que se propuseram a contribuir na pesquisa (considerando que 73 egressos não foram localizados, e outros 13 alegaram não poder ajudar). O questionário foi aplicado com a intencionalidade de averiguar, inicialmente, o perfil dos jovens trabalhadores egressos (situação laboral, renda, moradia, faixa etária, sexo, estado civil, escolaridade) e, posteriormente, identificar como a sua formação contribuiu para a inserção no mundo do trabalho.

Por conseguinte, foi realizada a entrevista semiestruturada, que é uma técnica de coleta de informações sobre um determinado assunto, diretamente solicitada aos sujeitos pesquisados, havendo uma interação, quando o pesquisador visa a apreender o que os sujeitos pensam, sabem, representam, fazem e argumentam (SEVERINO, 2002).

A partir disso, selecionou-se uma amostragem de 12 sujeitos, dos quais foram localizados 9. Destes, apenas 5 responderam, com base nos seguintes critérios: Idade: sujeito com maior e menor idade; Tempo de serviço: sujeito com maior tempo de serviço; e escolaridade: sujeito com maior e menor nível de escolaridade. Essas informações foram trabalhadas com ética, resguardando as informações e identificação pessoal dos entrevistados. Usou-se a entrevista com a intencionalidade de identificar a situação laboral dos egressos e investigar o grau de satisfação com a sua área de formação.

Por fim, foi feita a sistematização e a análise dos dados coletados de todas as etapas da pesquisa, com base na Análise de Conteúdo ( $A C)$, que é um conjunto de técnicas de análise das comunicações, pontuadas na pesquisa de campo que, por meio de procedimentos sistemáticos e objetivos da descrição do conteúdo das comunicações indicadoras, permite a indução e a conclusão dos conhecimentos referentes às categorias de produção/recepção das mensagens (BARDIN, 2011).

Este artigo está estruturado em dois pontos principais: o primeiro volta-se para a discussão da relação entre trabalho e universidade na formação na educação a distância, enquanto o segundo ponto analisa as contradições do perfil de jovens trabalhadores egressos da educação a distância no Pará.

\section{A RELAÇÃO ENTRE TRABALHO E UNIVERSIDADE NA FORMAÇÃO NA EDUCAÇÃO A DISTÂNCIA}

Os resultados da pesquisa explicitam que os egressos, em sua maioria, são trabaIhadores, ou seja, realizam alguma ocupação, aspecto esse bastante significativo, pois, de acordo com Lukács (1978), “[...] não é apenas uma forma histórica do trabalho em 
sociedade, ele é a atividade fundamental pela qual o ser humano se humaniza, se cria, se expande, se aperfeiçoa". O homem, portanto, forma-se por intermédio do seu trabalho, fazendo uso desse trabalho para se inserir na sociedade.

Para Marx (1983), é justamente essa capacidade que o homem tem de transmitir significado à natureza, por meio de uma atividade planejada, consciente e que envolve uma dupla transformação entre o homem e a natureza, que diferencia o trabalho do homem daquele realizado por qualquer outro animal. É mediante o trabalho que o homem transforma a si e a natureza ao seu redor, de acordo com as suas necessidades.

Constituindo a universidade um papel fundamental para a formação de profissionais ao mundo do trabalho, e simultaneamente para a produção de conhecimentos, entende-se o trabalho enquanto produtor de cultura e, portanto, de humanização do homem. Por isso, a universidade precisa apresentar, para os jovens, uma possibilidade de formação que negue uma concepção técnica e instrumental homogeneizada, caminhando em uma perspectiva de formação cada vez mais humana. Para que, nesse aspecto, ocorra o conhecimento, produzido na academia como parte humanizadora do homem, este precisa ser fertilizado com o meio social, conforme afirma Severino (2002), posto que o conhecimento produzido, para se tornar ferramenta apropriada de intencionalidades das práticas mediadoras da existência humana, precisa ser disseminado e repassado, ou seja, colocado em condições de universalização.

Concomitante a isso, apesar das diversas críticas que a instituição pesquisada sofre em relação aos seus ideários, a maioria dos seus egressos trabalha em sua área de formação, o que significa afirmar que, mesmo com todas as contradições existentes para essa modalidade de educação, os sujeitos dali oriundos adentram no mercado de trabalho, exercendo a formação que foi recebida na instituição. É importante ressaltar, no entanto, que esses dados não são regra, pois se entende que muitos criam uma falsa ilusão ou expectativa de que, ao concluírem o curso, consequentemente, adentrarão no mercado de trabalho, principalmente atuando em sua área de formação, isso por conta da ideologia da empregabilidade, como afirma Ramos (2014, p. 57):

A ideologia da empregabilidade que difundiu a ideia de que, quanto mais capacitado o trabalhador, maiores as suas chances de ingressar e/ou permanecer no mercado de trabalho. Seduzida por essas ideologias, a classe trabalhadora passou a se mobilizar pela melhoria dos seus padrões de escolarização.

Difundir essa ideia significa afirmar que os sujeitos que adentrarem em um curso de Ensino Superior automaticamente estarão no mercado de trabalho. É sabido, todavia, que a realidade é outra: trata-se de um mercado de trabalho competitivo e limitado, em que poucos têm a mesma oportunidade. Nesse sentido, muitos indivíduos optam por trabalhos que não correspondem à sua área de formação. Como afirma Marx (1983), o trabalho no modo de produção capitalista deixa de hominizar e passa a alienar, uma vez que o produto e o próprio processo de produção se tornam estranhos ao trabalhador. O capitalismo modifica a visão de liberdade do homem, na medida em que este precisa vender a sua força de trabalho para sobreviver, dissociando-se, portanto, o trabalho do homem que o realiza. 
Observa-se que, apesar de muitas tentativas de entrar em uma universidade pública e presencial, os entrevistados não obtiveram aprovação por conta de um sistema que limita as vagas; isso quando se mencionam tempos passados recentes. Essa situação, contudo, ainda permanece, como demonstra a Universidade Federal do Pará, a qual, no ano de 2018, como já referenciando anteriormente, de acordo com o seu site oficial, ofertou 7.286 vagas para um montante de 88.376 candidatos inscritos. Diante disso, constata-se que as vagas ofertadas são muito limitadas para atender à demanda da comunidade.

\section{REFLEXÕES SOBRE O PERFIL DE JOVENS TRABALHADORES EGRESSOS DA EDUCAÇÃO A DISTÂNCIA NO PARÁ}

Após a conclusão da aplicação dos questionários, assim como após a elaboração da entrevista, foi realizada a etapa de organização e de sistematização dos dados coletados, quando se fez necessário realizar reflexões sobre algumas informações relevantes para a compreensão do perfil dos egressos do curso de Pedagogia da modalidade EaD.

A categoria "jovens trabalhadores egressos" deriva de uma definição de base marxista, que considera a faixa etária (71\% dos sujeitos possuem entre 29 a 39 anos de idade), mas, principalmente, a sua condição de classe social. Muitos desses jovens são egressos da Educação a Distância, vivenciaram cursos com a utilização de ambientes virtuais de aprendizagem e são oriundos de famílias de baixa renda, que vivem da sua força de trabalho. Podem, portanto, ser classificados como pertencentes a uma das classes sociais fundamentais, a saber: os trabalhadores.

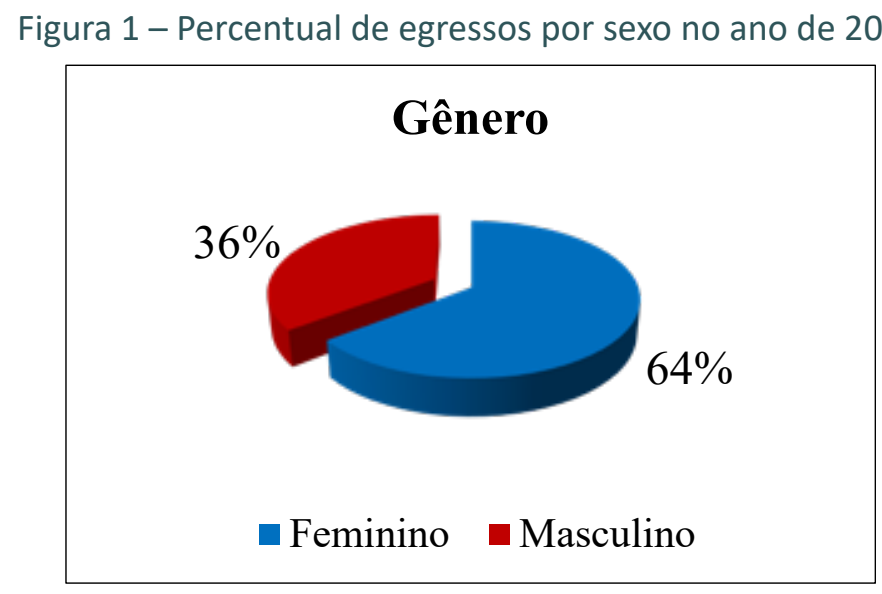

Fonte: Pesquisa de Campo, 2019.

A presença da mulher nos cursos de Graduação a distância, representada pelo percentual de $64 \%$, segue uma tendência histórica da luta, constituindo-se em um dado que possibilita entender que a expansão do acesso e da permanência para o Ensino Superior ajuda no processo de humanização da sociedade como um todo.

A maior parte do alunado e dos concluintes dos cursos superiores no contexto dessa expansão é do sexo feminino e se concentra em cursos feminizados (ROSEMBERG, 2002), como é o caso das licenciaturas preparatórias ao magistério, como se 
demonstrará a seguir. Por isso, a importância de se investigar a educação superior da perspectiva de gênero (PROJETO RIAIPE 3, 2010) (BARBOSA; CARVALHO; LOPEZ, 2018, p. 151).

Articulando-se a questão do gênero com a faixa etária dos sujeitos desta pesquisa, pode-se perceber a grande relevância desses dados no que se refere ao processo de enfrentamento e de lutas contra o preconceito, o machismo e o patriarcado em nossa sociedade e na universidade.

Figura 2 - Faixa etária dos egressos no ano de 2018

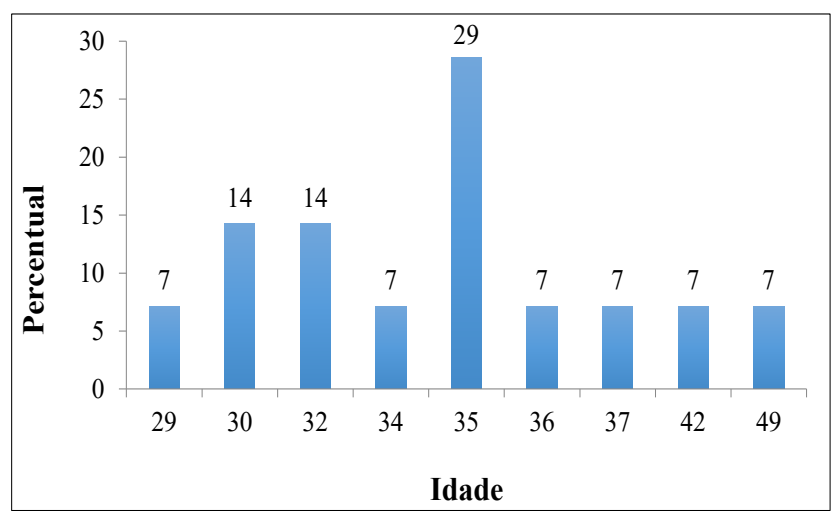

Fonte: Pesquisa de Campo, 2019

Os dados da pesquisa demonstram que há uma predominância do sexo feminino (64\%) sobre o sexo masculino (36\%). Quanto à idade, corresponde-se à faixa etária entre 29 a 49 anos, sendo o maior percentual correspondente a 35 anos, com 29\%. Por conseguinte, ficam empatadas as idades de 30 e 32 anos, com 14\%, respectivamente.

Figura 3 - Localidade dos egressos no ano de 2018

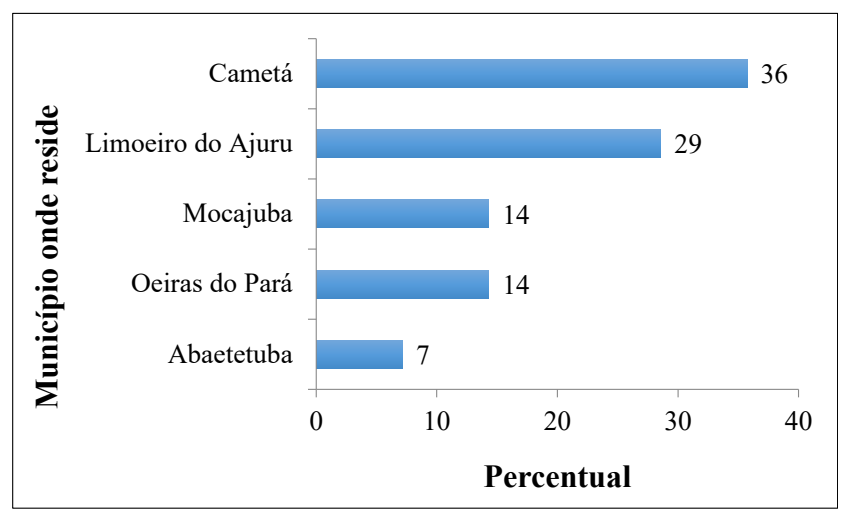

Fonte: Pesquisa de Campo, 2019

Com relação à localidade de residência, a maioria não reside no município onde a pesquisa foi realizada. No município de Cametá residem 39\%, enquanto $64 \%$ residem em outros municípios, contabilizando $29 \%$ em Limoeiro do Ajuru, 14\% em Mocajuba, 14\% em Oeiras do Pará e 7\% em Abaetetuba, o que implica para o fato de o número de localizados ser pequeno, como é ilustrado nas Figuras 1, 2 e 3, respectivamente. 
Com relação às questões mais abrangentes, relacionadas com a empregabilidade, constatou-se que a maioria dos pesquisados trabalha, como representado na Figura 4.

Figura 4 - Percentual de egressos trabalhadores no ano de 2018

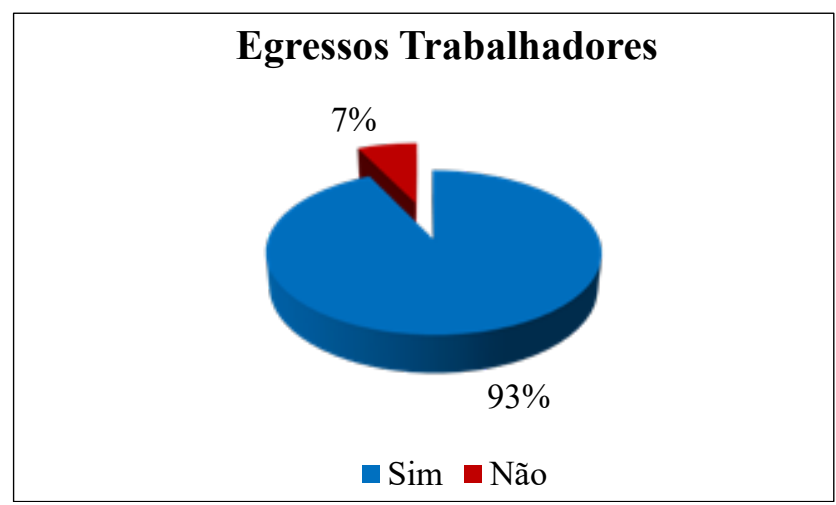

Fonte: Pesquisa de Campo, 2019.

As presentes análises mostram, também, que a maioria dos pesquisados realiza algum tipo de trabalho/ocupação, ficando subdividido esse trabalho em formal e informal, contendo, ainda, um pequeno percentual correspondente aos que não trabalham, como mostra a Figura 5, a seguir. Esses dados evidenciam como se articulam universidade e trabalho no processo formativo por meio da educação a distância. Mostram, ainda, que $o$ acesso aos postos de trabalhos formais revela que os cursos contribuíram de forma efetiva para o acesso ao mercado de trabalho.

Figura 5 - Percentual do vínculo empregatício dos egressos no ano de 2018

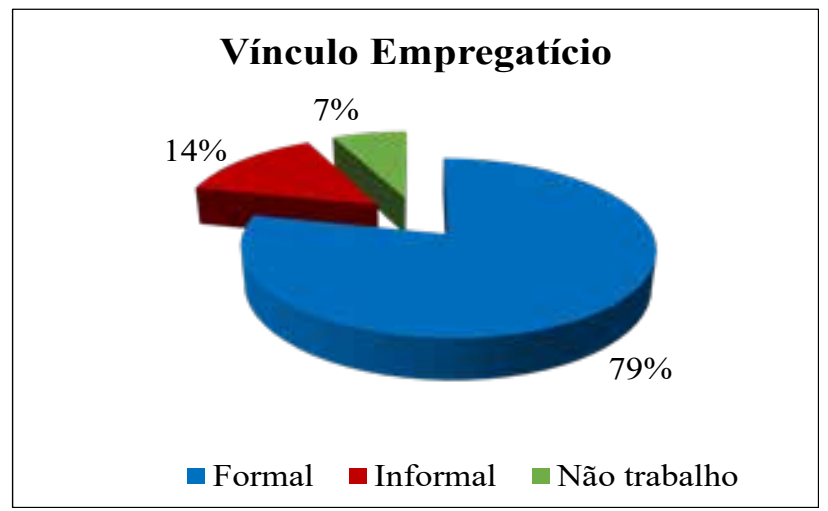

Fonte: Pesquisa de Campo, 2019.

Com relação à área de atuação, há um número considerado de egressos que trabalham em sua área de atuação, correspondendo a $64 \%$ do total, e que apenas $36 \%$ não atuam, como representa a Figura 6, a seguir. 
Figura 6 - Percentual de trabalhadores que atuam ou não na sua área de formação no ano de 2018

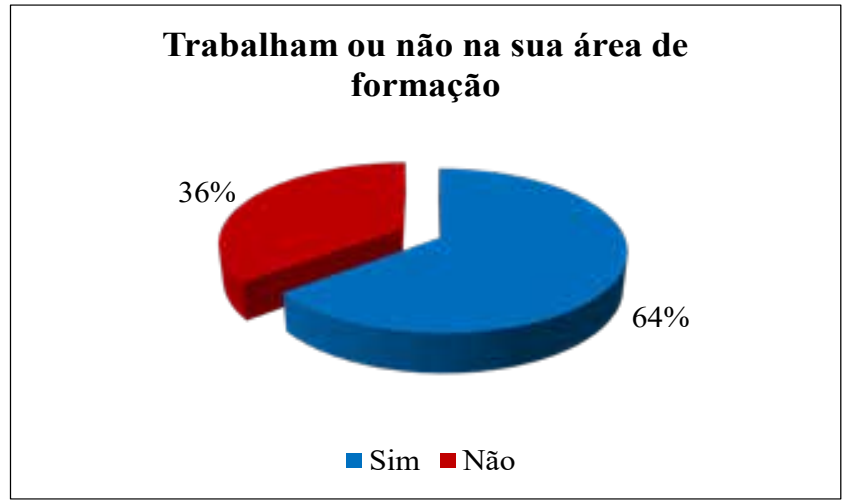

Fonte: Pesquisa de Campo, 2019.

A Figura 7 mostrará qual é a área de atuação destes, sendo possível observar que, dentre as opções relatadas, a maioria respondeu atuar como professor/a. Significa, portanto, que estão atuando na sua área de formação.

Sendo assim, é possível dizer que a noção de desenvolvimento profissional, no contexto educacional da atualidade, liga-se às concepções de formação permanente, formação contínua, formação em serviço e aprendizagem ao longo da vida. Tendo em vista esses pressupostos, propõe-se considerar que a prática pedagógica como tutor virtual em cursos EaD mediados por TDIC contribui para o desenvolvimento profissional docente ao favorecer a aprendizagem contínua pela reflexão acerca das situações vivenciadas nesse contexto (CHAQUIME; MILL, 2016, p. 121).

Assim, a formação de professores em plataformas de educação a distância constitui-se como um desafio de grande envergadura para as instituições públicas e privadas, principalmente no que diz respeito ao processo de formação de professores para a Educação Básica por meio do curso de Pedagogia.

Figura 7 - Percentual da área de atuação dos egressos no ano de 2018

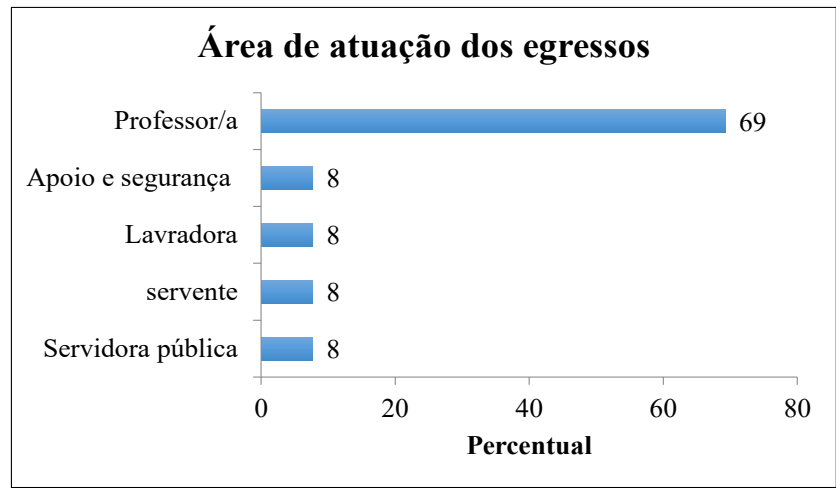

Fonte: Pesquisa de Campo, 2019.

Posteriormente, uma das indagações realizadas relacionou-se ao motivo que os levaram a escolher o curso. Diante do questionário aplicado, o resultado obtido foi que $43 \%$ alegaram ser Pedagogia o curso que desejavam fazer, percentual esse que se igualou com aquele dos que responderam "eu já trabalho na área", com 43\%, conforme representado na Figura 8. 
Figura 8 - Percentual do motivo da escolha do curso dos egressos no ano de 2018

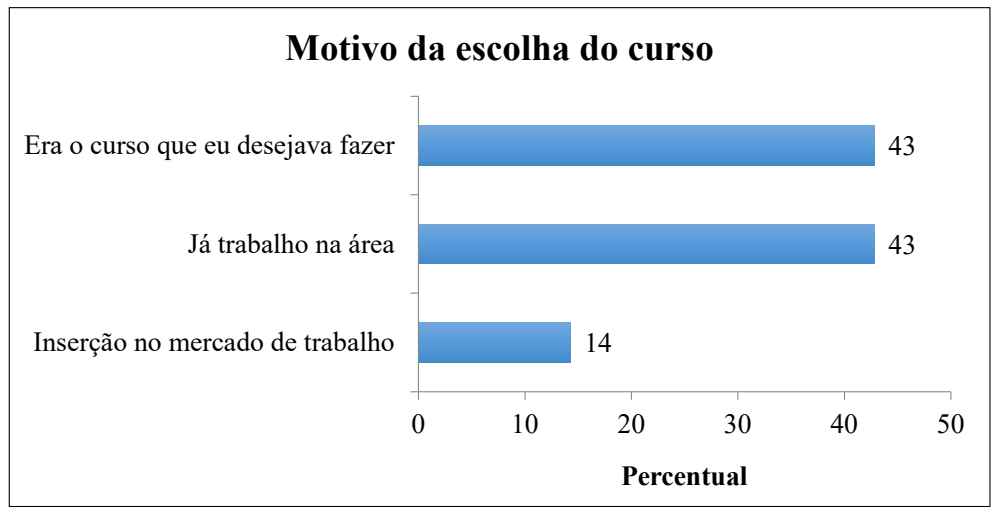

Fonte: Pesquisa de Campo, 2019.

Esses dados explicitam os motivos que levaram esses sujeitos a escolherem os cursos de EaD. Dialogando com Costa (2016), pode-se entender que os principais motivos são: 1. Respeito ao ritmo e disponibilidade de tempo de cada aluno; 2 . Universalização do ensino; 3. Modalidade educacional flexível, aberta e interativa; 4 . Renasce a prática de leitura e escrita (ciberescrita), forma básica de comunicação via web.

Outro aspecto observado está no fato de que uma parcela significativa dos egressos trabalhadores pesquisados, ao responderem à questão de qual seria a principal razão para terem escolhido essa Instituição de Ensino Superior, informou que foi a falta de tempo para realizar um curso presencial, posto que a instituição na modalidade a distância possibilita a flexibilidade de tempo e espaço, uma vez que o discente não precisa estar na instituição de ensino todos os dias, precisando ir apenas uma vez, possibilitando, assim, no decorrer dos outros dias, estudar em qualquer lugar fora do ambiente acadêmico, conforme representado na Figura 9, a seguir.

Figura 9 - Percentual da razão para os egressos terem escolhidos cursar o Ensino Superior no ano de 2018

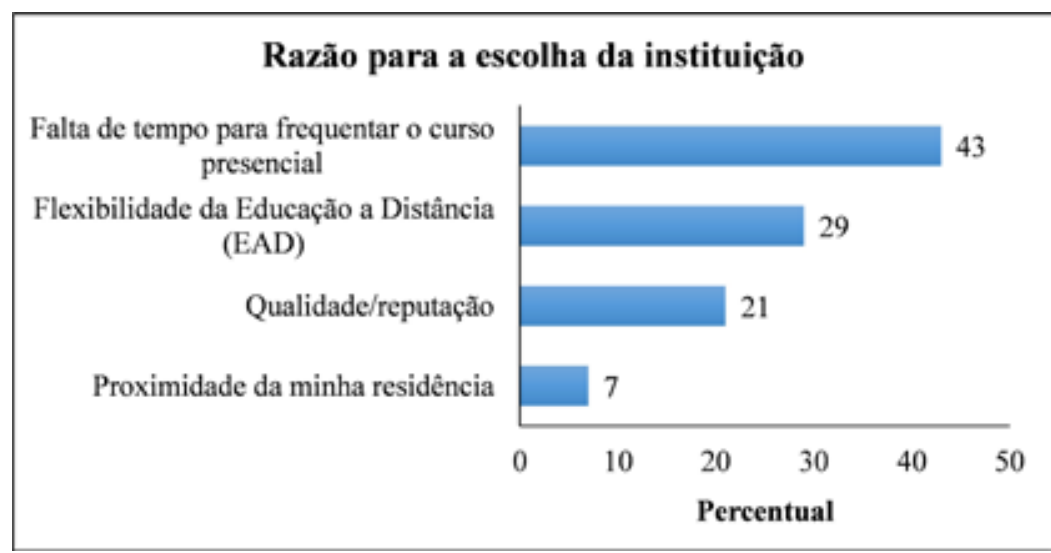

Fonte: Pesquisa de Campo, 2019.

Com relação à entrevista, foram coletadas falas significativas, a fim de entender e ressaltar alguns conceitos fundamentais desta pesquisa, tais como: universidade, formação profissional, formação humana, educação a distância e condições de trabalho, assim como para compreender aspectos de forma mais explicitada sobre os egressos. 
Para a entrevista, foram selecionados 12 egressos, respeitando-se os critérios a seguir expostos, sendo localizados somente 9 desses egressos. Deste montante, somente 5 dos sujeitos deu retorno, como mostra a Tabela a seguir.

Tabela 1 - Critérios utilizados para realizar a entrevistas, assim como os egressos entrevistados

\begin{tabular}{l|l|l}
\hline \multicolumn{2}{l}{ Critérios para seleção da amostragem } & Entrevistado \\
\hline \multirow{2}{*}{ Idade } & Maior idade & $---\cdot-----$ \\
\hline \multirow{2}{*}{ Tempo de serviço } & Menor idade & Egresso B \\
\hline \multirow{2}{*}{ Escolaridade } & Maior tempo & Egresso E \\
\hline & Menor tempo & Egresso A \\
\hline & Maior nível & Egresso D \\
\hline & Menor nível & Egresso C \\
\hline
\end{tabular}

Fonte: Pesquisa de Campo, 2019.

Assim, a partir dos dados coletados nas entrevistas, quando questionado sobre qual a contribuição do curso realizado na instituição para sua formação, no aspecto profissional, a egressa " $\mathrm{A}$ " destaca:

[...] O Curso de Pedagogia que realizei foi de suma importância para minha formação e realização tanto profissional quanto pessoal, pois me direcionou ao caminho o qual queria seguir de forma convicta, haja vista, que me proporcionou uma formação de nível superior na área que desejava e me preparou não só como professora, mas também como pessoa capaz de compreender e colaborar para a melhoria da qualidade de vida dos alunos (EGRESSA “ $A$ ", 2019).

Ressalta-se, a partir desse ponto, a categoria "universidade", destacada na fala da entrevistada, quando, na concepção da mesma, é entendida como uma "instituição social, e como tal exprime de maneira determinada a estrutura e o modo de funcionamento da sociedade como um todo" (CHAUÍ, 2003, p. 5).

Ainda sobre a mesma pergunta, agora relacionada à concepção de formação profissional, e no sentido de que a instituição, assim como o curso, possibilita com que se esteja mais preparado para adentrar no mercado de trabalho, ressalta o egresso " $C$ ":

[...] Para mim, ter um curso de formação me deu também oportunidade no mercado de trabalho. Vejo que ela contribuiu bastante para a minha vida, porque hoje eu, com 42 anos, se não tivesse um curso de Graduação, a gente não é bem visto pela sociedade (EGRESSO "C", 2019).

Da mesma forma, relata a egressa "B":

[...] O curso contribuiu muito para minha formação profissional, pois todo o conhecimento adquirido no decorrer de minha Graduação foi aplicado em sala de aula (EGRESSA "B", 2019).

Esses dados possibilitam pensar e refletir sobre a função social da universidade na sociedade nesse momento histórico, marcado pela importância da formação de trabaIhadores. 
A universidade confronta-se com essas diferentes e antitéticas perspectivas de atuação, ou diferentes e antitéticas funções sociais, a fim de produzir ciência e tecnologia para o capital, ou produzir ciência e tecnologia, por meio de um projeto coletivo de sociedade, fundado nos interesses dos trabalhadores. Em outros termos, a universidade, por não se constituir em uma ilha, apesar da defesa da autonomia, "sofre" as interferências dos interesses do capital perpassando as suas práticas, interesses, esses, marcados por práticas produtivas do capitalismo periférico e dependente do capital internacional (SILVA, 2019, p. 65).

No que se refere à concepção de formação humana, o questionamento foi: Qual a contribuição do curso realizado para a sua formação no aspecto humano? Sobre esse questionamento, averiguou-se que o curso oferecido pela instituição investigada possibilitou, aos egressos, o desenvolvimento de uma visão mais ampla sobre essa categoria, conforme relatado pela egressa " $\mathrm{B}$ ":

[...] E quanto ao aspecto humanista, o curso me ajudou a olhar as pessoas pelo lado mais humano, sendo que a minha Graduação foi em pedagogia. Por meio deste eu consegui adquirir conceitos que me tornaram mais sensível a algumas situações enfrentadas no contexto escolar (EGRESSA "B", 2019).

Infere-se, na fala do egresso, a ênfase dada às contribuições do Curso de Pedagogia no que se refere ao seu processo de humanização, o que também é reafirmado na fala do egresso " $E$ ":

[...] A contribuição está no fato do curso proporcionar o contato com diversos teórico, entre eles, cito Paulo Freire e sua ação educativa-crítica. Uma pedagogia fundada na ética, no respeito à dignidade e à própria autonomia do educando. Essas questões nos formam como seres humanos, na medida em que nos faz tomar consciência de nossa condição de responsabilidade ética no mundo (EGRESSO "E", 2019).

Relacionado à concepção de educação a distância, é importante destacar qual a visão desses egressos em relação a esse conceito, por meio de uso de algumas perguntas como: Quais motivos levaram você a realizar um curso a distância? E quais foram os pontos positivos e negativos do processo formativo? Sobre essa questão, ressalta a egressa " $B$ ":

[...] Um dos principais motivos foi a disponibilidade do curso. Apesar de ser uma universidade particular, era mais acessível à minha realidade na época em que eu realizei meu curso. Outro motivo foi também pela Universidade ser credenciada ao MEC. Na época eu tinha sido aprovada no concurso público municipal e precisava de uma Graduação (EGRESSA "B", 2019).

A egressa " $A$ ", por sua vez, salienta que:

[...] Primeiramente, tinha tentado o vestibular tradicional, que na época acontecia em duas fases. Não era como hoje, não existia ENEM e nem uma das possibilidades que nos garantisse mais chance de ingressar na faculdade de forma mais "fácil". Porém, não obtive aprovação. Isso me desestimulou bastante, então, mediante a realidade temporal, comecei a pensar que esperar passar no vestibular seria perda de tempo. Contudo, resolvi procurar uma instituição particular, até mesmo porque 
já estava atuando como docente e precisava ao menos estar cursando Pedagogia para garantir o meu emprego. Além de que desejava muito ser formada na área de atuação (EGRESSA “A”, 2019).

De outro modo, destaca o egresso " $\mathrm{C}$ ":

[...] O motivo é que meu interior não oferece curso regular. Há anos atrás, aqui entrou a Ufpa, mas como a gente já estava numa idade avançada e já estava em andamento no curso, continuei com o curso que já estava em andamento, pelo fato que não tinha mesmo uma presencial aqui no município (EGRESSO “C", 2019).

Ainda sobre essa concepção foi feito o seguinte questionamento: Quais foram os pontos positivos e negativos do processo formativo? Como resposta, o egresso "E" asseverou:

[...] Flexibilidade de horário de estudo e dias. Avalio como ponto negativa a questão de um tutor por turma, um único orientador para todas as disciplinas do curso. Certamente isso foi um entrave para o aprofundamento de diversas questões conceituais (EGRESSO “E”, 2019).

Destaca-se, ainda, o egresso " $C$ ", o qual ressalta:

[...] Um dos pontos positivos é que ela é flexível, me dá o direito de estudar em horas vagas e me apresentar todo fim de semana lá no Polo: esse é o ponto positivo. Agora um dos pontos negativos é que, muitas vezes, o próprio Polo não dá suporte pra gente. Como, às vezes, têm tutores que são professores de muitas funções, eles não são daquela área [...] e só vive trocando de tutor e não existe um tutor específico pra cada área que o aluno está concluindo, e isso dificulta muito [...], e o tutor não dar suporte pra gente de tirar minhas dúvidas, de como fazer, como resolver certas questões (EGRESSO “C”, 2019).

Outro aspecto negativo da Instituição está relacionado com a fala do egresso " $\mathrm{C}$ ", quando questionado da seguinte forma: Enquanto egresso, você se sente satisfeito com a formação recebida, ou esta não correspondeu com as suas expectativas? Esse questionamento é necessário para que se possa pensar, fundamentando-se em Sacristán (1999), sobre a desprofissionalização da docência, quando esse autor dispõe que o status social dos professores passou de semiprofissão para um processo de proletarização. Seu argumento baseia-se em duas razões: primeiramente, o fato de que os docentes dependem de diretrizes político-administrativas que regulam o sistema educativo, de cuja definição não participam; em segundo lugar, porque os professores dependem das condições impostas pelos postos de trabalho para desenvolver a sua atividade.

O egresso " $C$ ", então, afirma:

[...] Ela não correspondeu da seguinte forma, porque eu achei uma Graduação fraca. Isso depende de cada graduando em buscar conhecimento, correr atrás, fazer os trabalhos e correr atrás dos estágios, depende de cada pessoa a formação. Se fosse depender mesmo da minha faculdade, [...] e aí pra gente ser um profissional realmente a gente tem que correr atrás. Ela deixa lacunas aberta, os Polos, às vezes, não dão suporte [...] é preciso ter uma fiscalização da sede aqui no Polo para ver se as coisas melhoram (EGRESSO “C", 2019).

Por outro lado, a egressa " $A$ " destaca: 
[...] Me sinto bastante satisfeita com a formação que recebi. A mesma correspondeu com minhas expectativas, pois tudo ocorreu dentro do esperado. E destaco sempre até mesmo com meus alunos que "Instituição nenhuma, por mais renomada que seja, forma um bom profissional, se este não for perseverante, persistente e realmente determinado a alcançar seus objetivos". Eu ingressei determinada não apenas a conquistar um diploma de Nível Superior, mas de me tornar uma profissional qualificada, e acreditei em mim desde o início (EGRESSA "A", 2019).

Falar de egressos e de suas sucessivas formações alude também a relacionar de que forma o processo de ensino e aprendizagem implica, hoje, em suas vidas, e, principalmente, em sua atuação. Diante disso, questionou-se aos mesmos: Ao desempenhar sua atividade laboral, ou seja, a prática, quais os aspectos que você percebe serem resultantes das teorias aprendidas no curso? O egresso " $E$ " assim se refere:

[...] São muitos os aspectos que envolve esse processo de ensino-aprendizagem, dentre esses quando se fala de Educação Infantil. Algo que muito utilizo na minha metodologia de ensino e que trago das teorias aprendidas são as formas de ensinar através da ludicidade; a criança aprende brincando. É por meio do brincar que a aprendizagem se torna mais prazerosa, divertida e dinâmica, assim há maior interação entre os alunos que se envolvem espontaneamente nas brincadeiras e aprendem com mais facilidade. A afetividade também é um ponto muito importante nesse processo. A criança é aberta às emoções; tudo que se faz vai refletir nesse aspecto, seja de forma positiva ou negativa, daí a importância de trabalhar os eixos que norteiam a Educação Infantil: educar, cuidar e brincar (EGRESSA "E", 2019).

Posterior a isso, foi feita a seguinte pergunta: Quais foram os principais motivos que o levaram à escolha do seu trabalho atual? Em resposta, a egressa " $B$ " ressalta:

[...] Primeiramente, foi a falta de opção no mercado de trabalho; eu tinha formação em magistério. Então, eu consegui um emprego para dar aula, porém, eu me sinto realizada em minha profissão (EGRESSA “B", 2019).

Uma outra questão alcançada com a entrevista refere-se ao seguinte: Quanto ao seu vínculo de trabalho, este "sofre" interferência da precariedade do trabalho que se vivencia atualmente? A partir desse questionamento, possibilita-se entender como está se realizando esse trabalho, conforme fala da egressa " $\mathrm{A}$ ":

[...] Sim. Trabalhar na área da educação não é fácil, são muitos os desafios, as dificuldades, seja elas econômicas, estruturais, sociais ou políticas, tudo interfere. Os obstáculos surgem todo tempo, uma vez que você quer fazer o melhor para desenvolver um bom trabalho, mas o sistema nem sempre contribui para que esse melhoramento aconteça, haja vista que a educação é a arma mais poderosa para derrubar um sistema opressor que se pode usar para mudar o mundo, com disse Nelson (EGRESSA “A”, 2019).

Por conseguinte, fez-se o seguinte questionamento: Você se sente satisfeito ou realizado profissionalmente? Em resposta, a egressa " $A$ " destaca:

[...] Eu, tanto pessoal quanto profissionalmente, me sinto muito satisfeita e realizadíssima com minha profissão; sou pedagoga, Especialista em Educação Infantil e em Gestão pela mesma instituição e Graduada em Letras Língua Portuguesa pela Ufpa. Lutei muito, passei por diversas situações fáceis e difíceis, estudei muito para 
alcançar meus objetivos e consegui. Hoje, tenho meu trabalho reconhecido, sou respeitada como profissional, atuo na área e com pessoas que gosto, vivo tranquilamente e tenho todos os meus sonhos realizados (EGRESSA " $A$ ", 2019).

Por sua vez, outro egresso assevera:

[...] Não. É frustrante, porque a gente passa 4 anos e meio fazendo o Curso de Pedagogia e quando eu acabei, passei mais um ano e meio fazendo Pós, e estou fora do mercado de trabalho [...] Isso torna frustrante porque, às vezes, têm colegas, colegas de formação, eles não tão se formando porque eles têm responsabilidade de estar em sala de aula, eles estão se formando apenas para ter um certificado (EGRESSO “C", 2019).

Em relação aos dados da Figura 8, acerca do motivo de escolha do curso, esses dados correspondem a algo significativo para a pesquisa, relacionado ao fato de que $43 \%$ dos egressos escolheram o curso por já estarem atuando como docentes. Ou seja, eles faziam parte do grupo de professores atuantes com o magistério e que precisavam de uma qualificação, a fim de melhor estarem preparados para as oportunidades existentes no mercado de trabalho, que são extremamente escassas e cada vez mais seletivas.

Relacionado ao fator determinante para a escolha da Instituição, destaca-se que um dos principais motivos encontra-se na falta de tempo para frequentar um curso presencial, posto que grande parte dos egressos reside em municípios que não oferecem cursos presenciais, tendo de se deslocarem para outras localidades, além do histórico de muitas tentativas fracassadas em adentrar no âmbito de um curso presencial, como visto anteriormente no relato da egressa " $\mathrm{A}$ ".

Outro aspecto bastante frisado corresponde ao fato de a Instituição oferecer a flexibilidade, como lembra o entrevistado " $C$ ": "[...] ela é flexível, me dá direito de estudar em horas vagas, e me apresentar todo fim de semana lá no Polo". Esse é um dos principais pontos positivos da Instituição: proporcionar flexibilidade de tempo, de lugar, de oportunizar o estabelecimento do próprio ritmo de estudo, etc.

A partir disso, é possível entender qual o conceito de universidade que os egressos têm. Isso destaca-se na primeira fala do entrevistado " $E$ ", quando este reforça a ideia de que a instituição contribuiu muito para a sua vida, possibilitando que compreendesse melhor o mundo à sua volta. Segundo Kunz (1999), a universidade tem como função principal formar o cidadão, desenvolvendo a sua consciência crítica, contribuindo para o desenvolvimento humano, para o bem-estar da sociedade, para o bom funcionamento das relações sociais e para a reflexão dos valores.

Diante disso, de acordo com o entrevistado " $C$ ", quando questionado sobre a contribuição da instituição para a sua formação profissional, ele ressalta que foi importante, apesar de, atualmente, não estar trabalhando, o que significa afirmar que o curso é importante profissionalmente para a obtenção de um trabalho e, também, para que ele se sinta inserido socialmente na sociedade. Moran et al. (2004) ensinam que, devido ao mercado globalizado ser cada vez mais exigente e dinâmico, a Educação a Distância vem sendo uma ferramenta de acesso ao conhecimento cada vez mais utilizada pela população. 
Compreende-se, também, que, de acordo com os dados apresentados anteriormente, com relação à formação humana os entrevistados destacaram que a Instituição contribuiu bastante para esse aspecto, possibilitando que o curso proporcionasse o contato com a ideia de diversos autores e que, a partir disso, foi possível proporcionar uma concepção ética, autônoma e humana, a qual é aplicada no dia a dia desses sujeitos.

Desde que foi inserida no contexto brasileiro, no entanto, essa modalidade sofreu e sofre, até hoje, diversas críticas. Uma delas diz respeito à tentativa de massificação e à expansão de forma quantitativa. Se por um lado ela vem ampliar o acesso a quem não tem, por outro ela levanta questões bastante presentes, como expansão da educação numa visão capitalista, a pouca qualidade do ensino ofertado e a desvalorização do papel do professor, este sendo substituído por tutores, como bem relata o entrevistado " $C$ " no tocante ao resultado apresentado anteriormente, quando são trazidos pontos para serem pensados sobre a metodologia utilizada em sala de aula, nos quais, de acordo com o entrevistado, o sujeito tem de comparecer uma vez por semana no Polo para realizar uma prova semanal, sendo essa aula mediada pelo tutor, o que, segundo Ferreira e Rezende (2003):

É um sistema de ação docente que propicia a mediação e a facilitação da aprendizagem, em educação a distância, com o fim de acompanhar e assessorar todo o processo de construção do conhecimento dos alunos envolvidos de forma a garantir a qualidade do processo ensino-aprendizagem (p. 2).

De acordo com a fala do egresso, porém, o tutor não tira todas as dúvidas dos sujeitos, e o restante do conteúdo das disciplinas fica mediado pela Plataforma Digital da Instituição, denominada Gioconda, à qual nem todos têm acesso ou sabem manusear.

A Gioconda é, portanto, a Plataforma em que alunos, colaboradores e empresas podem acessar o sistema acadêmico da Instituição, sendo um programa específico do Ambiente Virtual de Aprendizagem.

De acordo com o portal da Instituição, o Sistema Gioconda é utilizado desde 1999, sendo introduzido exclusivamente para os cursos presenciais, migrando em seguida para o EAD e, agora, voltando a integrar todos os produtos de Graduação da Instituição. Ocorre que, em 2017, a Instituição lançou uma nova versão do Sistema Acadêmico Gioconda, com o objetivo de facilitar a vida dos acadêmicos da Graduação a distância.

Ainda de acordo com o portal, é possível, com a Plataforma Gioconda, acessar notas, frequências, planos de ensino, ementas, conteúdos ministrados, solicitar documentos, cadastrar atividades complementares, gerar os boletos, calendários acadêmicos, etc., tendo por objetivo central facilitar a comunicação entre aluno/aluno, instituição/aluno e tutor/aluno. Compreende-se, no entanto, a partir da visão do entrevistado " $C$ ", que a relação tutor/aluno se deu de forma fragmentada, estando eles separados fisicamente por conta dessa especificidade que a Instituição apresenta, de realizar um encontro por semana, o que é utilizado para fazer a prova semanal, não havendo tempo para que os alunos tirem as suas dúvidas, tornando-se, assim, um dos impasses para se obter uma formação mais eficaz. 
Em contrapartida, conforme exposto na seção anterior, há o balanceamento entre essas afirmações, posto que a entrevistada " $\mathrm{A}$ " declara estar muito satisfeita com a educação recebida. Uma hipótese a ser considerada refere-se ao fato de que o entrevistado " $C$ " destaca pontos negativos, enquanto a entrevistada " $A$ " destaca pontos positivos. Por isso, infere-se que tais contradições correspondem com a circunstância de que o primeiro se encontra desempregado, enquanto a segunda se encontra bem e financeiramente estruturada. Isso significa que o item "inserção no mercado de trabalho" se apresenta como parâmetro de avaliação, haja vista que o sujeito desempregado avalia de forma negativa a formação recebida.

Em seguida, de acordo com os resultados referentes sobre a utilização, na prática, de aspectos provenientes de teorias vistas em sala de aula, observa-se que sim; isso condiz com a fala da entrevistada " $A$ ", uma vez que esse fator é bastante presente, principalmente no seu meio de trabalho; assim como destaca, também, a entrevistada " $B$ ", ao afirmar que "[...] são inúmeros os aspectos, principalmente na teoria utilizada por muitos educadores, dentre eles Paulo Freire, por exemplo, que é muito empregada na educação de nossas crianças". Outra questão que é importante evidenciar está contida na fala do entrevistado " $C$ ", quando ressalta:

[...] 50\% de cada teoria aprendida no Curso e $50 \%$ do próprio esforço porque Paulo Freire fala que ninguém se educa sozinho [...] quando chegam em sala de aula não sabem nada e devido à prática que a gente vai exercendo, devido a gente correr atrás, procurar parcerias com outros colegas que já têm experiência, que informam de que forma devemos agir, a gente começa a desenvolver um trabalho bacana, e quando a gente tem interesse e tempo para fazer nossos planos de aula, a gente desenvolve o trabalho de uma forma libertária (EGRESSO “C", 2019).

Percebe-se, na fala dos entrevistados, que ambos fazem uso dos referenciais teóricos vistos na Graduação em suas vidas, tanto no sentido profissional quanto humano, pois, diante da ideia supracitada, ninguém se educa sozinho, ou seja, um precisa do outro para que ambos se desenvolvam de forma completa e em sociedade.

Em seguida, fez-se a análise do motivo da escolha do trabalho atual desses egressos. De acordo com os resultados, especificamente com a entrevistada " $\mathrm{B}$ ", há a afirmação de que o trabalho não era necessariamente o que ela buscava, mas que há uma sintonia entre o trabalho e a sua formação. Ou seja, ela destaca que não era esse o trabalho que desejava, mas, por conta das circunstâncias, e também por conta de já possuir o magistério na área, começou a trabalhar e, posteriormente, a gostar, optando por ser formar nessa área, adquirindo, dessa forma, mais conhecimento para a sua atuação.

Pensar a educação escolar ou não escolar separada do mundo do trabalho, das relações sociais de produção, e dar-lhe como função precípua a formação do cidadão para a democracia (abstrata) é, uma vez mais, cair na armadilha que reserva uma escola de elite para a classe dirigente e uma "multiplicidade de escolas", que vão desde a escola formal desqualificada, "escolas profissionalizantes" (privadas ou público-privadas), de formação profissional (SENAI, SENAC, SENAR), treinamento na empresa até a "escola" das próprias relações capitalistas de trabalho no interior do processo produtivo, para a classe trabalhadora (FRIGOTTO, 2010, p. 210). 
Por conseguinte, esta reflexão ajuda a compreender a concepção dos sujeitos da pesquisa quando questionados se eles se sentem satisfeitos ou realizados profissionalmente. Nesse sentido, houve novamente contradições entre a fala do egresso " $C$ ", que ressalta não estar satisfeito, e que é frustrante se formar, se especializar e não adentrar ao mercado de trabalho, sendo destacadas nesse ponto as dificuldades de entrar no mercado de trabalho, este cada vez mais seletivo e competitivo e, muitas vezes, partidário, e a fala da entrevistada " $A$ ", que salienta estar satisfeita e bem realizada profissionalmente. Outra vez, nesse aspecto, há a dicotomia entre o grau de satisfação do que está inserido no mercado de trabalho contra o que não está.

\section{CONSIDERAÇÕES FINAIS}

As reflexões sobre os dados desta pesquisa acerca do perfil dos egressos dos cursos de EaD voltados para a formação de professores, como é o caso do curso de Pedagogia, permitem ressaltar a importância da universidade no processo formativo desse grupo significativo de jovens trabalhadores, que encontraram na EaD um espaço de formação e qualificação profissional.

Destaca-se que a concepção de EaD, no modo de produção capitalista, acabou determinando os sistemas de ensino enquanto preparação de trabalhadores idealizados, conforme as exigências e as demandas do processo produtivo, em que a EaD é apresentada como estratégia de desenvolvimento e democratização do acesso à educação, sobretudo para as pessoas situadas em regiões distantes dos centros urbanos e onde a rede pública de Educação Superior não consegue suprir toda a demanda da sociedade.

Após a análise e a interpretação dos dados coletados, em síntese, afirma-se que a educação oferecida pela Instituição, apesar das diversas críticas enfrentadas, contribui, de forma significativa, tanto no aspecto profissional quanto humano de seus sujeitos.

Conclui-se, também, que um dos aspectos destacados pelos resultados alcançados refere-se às contradições do perfil desses jovens universitários, os quais enfrentam os desafios de estudar e trabalhar concomitantemente. Outro aspecto destacado diz respeito à possibilidade da flexibilidade que a instituição apresenta em relação a horários, com a Plataforma Virtual proporcionando mais disponibilidade de acesso. Pode-se afirmar, ainda, que o fator negativo dessa modalidade se encontra no contexto da prática desenvolvida pelos tutores, considerando recurso tecnológicos, formação e capacidade de feedback, que não conseguem suprir as necessidades dos alunos, tornando a relação tutor/aluno um impasse para que o conhecimento se dê de forma eficaz.

\section{REFERÊNCIAS}

ALVES, N. Juventudes e inserção profissional. Lisboa: Educa, 2008.

ARRUDA, E. P.; ARRUDA, D. E. P. Educação a distância no Brasil: políticas e democratização do aceso ao ensino superior. Educação em Revista, Belo Horizonte, v. 31, n. 3, p. 321-338, jul./set. 2015.

BARBOSA, Rita Cristiana; CARVALHO, Maria Eulina Pessoa de; LOPEZ, Alejandra Montané. Inclusão educacional, digital e social de mulheres no interior da Paraíba: uma experiência na UFPB. Rev. Bras. Estud. Pedagog., Brasília, v. 99, n. 251, p. 148-171, jan. 2018. Disponível em: http://www.scielo.br/scielo.php?script=sci_arttext\&pid=S2176-66812018000100148\&lng=pt\&nrm=iso. Acesso em: 28 jun. 2020. DOI: http://dx.doi.org/10.24109/2176-6681.rbep.99i251.3409.

BARDIN, L. Análise de conteúdo. Tradução Luís Antero Reto e Augusto Pinheiro. São Paulo: Edições 70, 2011. 
BRASIL. Lei no 9394, de 20 de dezembro de 1996. Estabelece as diretrizes e bases da educação nacional. Brasília, DF, Presidência da República, 1996. Disponível em: http://bd.camara;gov.br/bd/bitstream/handle/bdcamara/19339/ldb_10ed.pdf?sequence=1. Acesso em: 4 fev. 2019.

BOCCATO, V. R. C. Metodologia da pesquisa bibliográfica na área odontológica e o artigo cientifico como forma de comunicação. Rev. Odontol. Univ. Cidade de São Paulo, São Paulo, v. 18, n. 3, p. 265-274, 2006. BOGDAN, R.; BILKEN, S. Investigação qualitativa em educação. Porto: Porto Editora, 1994.

CHAUÍ, M. A universidade pública sob nova perspectiva. Revista Brasileira de Educação, Rio de Janeiro, RJ, n. 24, p. 5-15, set./out./nov./dez. 2003.

COSTA, T. L. G. Metodologia do ensino a distância. Salvador, BA: Ufba, 2016. Disponível em: http://www. repositorio.ufba.br:8080/ri/bitstream/ri/25345/1/eBook_Metodologia_do_Ensino_a_Distancia-Ci\%C3\%AAncias_Contabeis_UFBA.pdf. Acesso em: 28 jun. 2020.

CHAQUIME, Luciane Penteado; MILL, Daniel. Dilemas da docência na educação a distância: um estudo sobre o desenvolvimento profissional na perspectiva dos tutores da Rede e-Tec Brasil. Rev. Bras. Estud. Pedagog., Brasília, v. 97, n. 245, p. 117-130, abr. 2016. Disponível em: http://www.scielo.br/scielo.php?script=sci_arttext\&pid=S2176-66812016000100117\&Ing=pt\&nrm=iso. Acesso em: 28 jun. 2020. DOI: https://doi.org/10.1590/S2176-6681/361514036

CHIZZOTTI, A. Pesquisa qualitativa em ciências humana e sociais. 3. ed. Petrópolis: Vozes, 2010.

FERREIRA, M. M. S.; REZENDE. R. S. R. O trabalho de tutoria assumido pelo programa de educação a distância da Universidade de Uberaba: um relato de experiência, 2003. Disponível em: www.abed.org?seminãrios2003/testo19.htm. Acesso em: 14 fev. 2020.

FRIGOTTO, G. O enfoque da dialética materialista histórica na pesquisa educacional. In: FAZENDA, I. (org.). Metodologia da pesquisa educacional. São Paulo: Cortez, 1991.

FRIGOTTO, G. A produtividade da escola improdutiva: um (re) exame das relações entre educação e estrutura econômico-social capitalista. 9. ed. São Paulo: Cortez, 2010.

KUNZ, I. Modalidades distintas na relação universidade/empresas e suas características específicas no Brasil. Curitiba: Ipardes, 1999.

LAKATOS, E. M.; MARCONI, M. de A. Fundamentos da metodologia científica. 5. ed. São Paulo: Atlas, 2003. LUKÁCS, G. As bases ontológicas do pensamento e da atividade do homem. Temas de Ciências Humanas, São Paulo, v. 4, p. 1-18, fev. 1978.

MARQUES, W. O quantitativo e o qualitativo na pesquisa educacional. Revista Avaliação, Sorocaba, SP, v. 2, n. 3-5, jul. 1997.

MARX, K. O capital: crítica da economia política. São Paulo: Abril Cultural, 1983. V. 1 (Os economistas).

MORAN, J. M. et al. Novas tecnologias e mediação pedagógica. 8. ed. Campinas: Papirus, 2004.

PORTAL DO CENTRO UNIVERSITÁRIO LEONARDO DA VINCI. Disponível em: https://home.uniasselvi.com. $\mathrm{br} /$. Acesso em: 14 fev. 2019a.

PORTAL DO CENTRO UNIVERSITÁRIO LEONARDO DA VINCI. Disponível em: https://portal.uniasselvi.com. $\mathrm{br} /$ noticias/tecnologia/gioconda-novo-ambiente acadêmico-esta-disponível-para-estudantes-de-ead. Acesso em: 14 fev. 2019b.

PORTAL DA UNIVERSIDADE FEDERAL DO PARÁ. Disponível em: https://www.portal.ufpa.br. Acesso em: 14 fev. 2019.

RAMOS, M. N. História e política da educação profissional. Curitiba: Instituto Federal do Paraná, 2014. V. 5. (Coleção formação pedagógica).

SACRISTÁN, J. G. Consciência e ação sobre a prática como libertação profissional dos professores. In: NÓVOA, A. (org.). Profissão professor. 2. ed. Porto: Porto Editora, 1999.

SEVERINO, A. J. Educação e universidade: conhecimento e construção da cidadania. Comunic. Saúde, Educ., Botucatu-SP, v. 6, n. 10, p. 117-24, fev. 2002.

SILVA, J. B. C. Universidade e trabalho na Amazônia. Curitiba, PR: Editora e Livraria Appris, 2019.

YIN, R. Estudo de caso: planejamento e métodos. 3. ed. Porto Alegre: Bookman, 2005. 